\title{
Floating macrolitter leaked from Europe into the
}

\section{ocean}

\author{
Daniel González-Fernández $\mathbb{1}^{1 凶}$, Andrés Cózar ${ }^{\circledR}$ ', Georg Hanke², Josué Viejo', \\ Carmen Morales-Caselles ${ }^{1}$, Rigers Bakiu ${ }^{3}$, Damià Barcelóo ${ }^{4,5}$, Filipa Bessa ${ }^{6}{ }^{6}$, Antoine Bruge ${ }^{7}$, \\ María Cabrera ${ }^{8}$, Javier Castro-Jiménez ${ }^{\circledR 9,26}$, Mel Constant ${ }^{10}{ }^{10}$, Roberto Crosti ${ }^{11}$, Yuri Galletti ${ }^{12}$, \\ Ahmet E. Kideys ${ }^{13}$, Nino Machitadze ${ }^{14}$, Joana Pereira de Brito ${ }^{15}$, Maria Pogojeva ${ }^{16}{ }^{16}$, Nuno Ratola ${ }^{17}$, \\ Júlia Rigueira ${ }^{18}$, Elisa Rojo-Nieto ${ }^{199,27}$, Oksana Savenko ${ }^{20,21}{ }^{20}$, Rosanna I. Schöneich-Argent ${ }^{22,28}$, \\ Grzegorz Siedlewicz ${ }^{23}$, Giuseppe Suaria $\circledast^{24}$ and Myrto Tourgeli ${ }^{25}$
}

\begin{abstract}
Riverine systems act as converging pathways for discarded litter within drainage basins, becoming key elements in gauging the transfer of mismanaged waste into the ocean. However, riverine litter data are scarce and biased towards microplastics, generally lacking information about larger items. Based on the first ever database of riverine floating macrolitter across Europe, we have estimated that between 307 and 925 million litter items are released annually from Europe into the ocean. The plastic fraction represented $82 \%$ of the observed litter, mainly fragments and single-use items (that is, bottles, packaging and bags). Our modelled estimates show that a major portion of the total litter loading is routed through small-sized drainage basins $\left(<100 \mathrm{~km}^{2}\right)$, indicating the relevance of small rivers, streams and coastal run-off. Moreover, the major contribution of high-income countries to the macrolitter inputs suggests that reducing ocean pollution cannot be achieved only by improving waste management, but also requires changing consumption habits and behaviour to curb waste generation at source. The inability of countries with well-developed recovery systems to control the leakage of waste into the environment further supports the need to regulate the production and use of plastic on a global scale.
\end{abstract}

T he input of solid waste from terrestrial sources to the world's oceans has become a major environmental threat, positioning marine litter and plastic pollution as priority issues in the international agenda ${ }^{1-4}$. If no effective measures are taken, the prospects for future growth in the production and use of plastics foresee an unsustainable increase in the amount of waste accumulated in terrestrial and aquatic ecosystems around the world ${ }^{5-7}$, with potential impacts on biodiversity and human health ${ }^{8,9}$.

Jambeck et al. ${ }^{10}$ provided a first approach to modelling mismanaged waste (MW), regarding items as waste if littered or inadequately disposed of on land. Considering the population within a $50-\mathrm{km}$ distance buffer from the coast and assuming a range of conversion rates to marine debris of between 15 and $40 \% \mathrm{MW}$, the authors estimated a global annual input of 4.8-12.7 million tonnes (Mt) of plastic to the marine environment. This range of conversion rates of MW to marine debris (15-40\%) was based on municipal water quality data gathered in the San Francisco Bay (California) watersheds. Field measurements of plastic input to the oceans are, however, essential for evaluating MW land-ocean transfer rates ${ }^{6,11,12}$, still leaving considerable room for improvement.

Rivers act as conduits to the ocean, funnelling the waste dumped into the drainage basins and, as such, they contribute to better understanding the input of litter to the ocean from terrestrial sources. Lebreton et al. ${ }^{11}$ and Schmidt et al. ${ }^{12}$ estimated the export

'Departamento de Biología, Instituto Universitario de Investigación Marina, University of Cádiz and European University of the Seas, Puerto Real, Spain. ${ }^{2}$ Joint Research Centre, European Commission, Ispra, Italy. ${ }^{3}$ Department of Aquaculture and Fisheries, Faculty of Agriculture and Environment, Agricultural University of Tirana, Tirane, Albania. ${ }^{4}$ Catalan Institute for Water Research (ICRA-CERCA), University of Girona, Girona, Spain. ${ }^{5}$ Water and Soil Research Group, Department of Environmental Chemistry, IDAEA-CSIC, Barcelona, Spain. ${ }^{6}$ Department of Life Sciences, MARE - Marine and Environmental Sciences Centre, University of Coimbra, Coimbra, Portugal. ${ }^{7}$ Surfrider Foundation Europe, Biarritz, France. ${ }^{8}$ Paisaje Limpio Association, Majadahonda, Spain. ${ }^{9}$ Mediterranean Institute of Oceanography, Aix Marseille University, University of Toulon, CNRS, IRD, Marseille, France. ${ }^{10} \mathrm{Centre}$ de Formation et de Recherche sur les Environnements Méditerranéens, Université de Perpignan Via Domitia UMR CNRS 5110, Perpignan, France. "BIO-SOST, Istituto Superiore per la Protezione e la Ricerca Ambientale, Rome, Italy. ${ }^{12}$ Biophysics Institute, CNR, Pisa, Italy. ${ }^{13}$ METU - Institute of Marine Sciences, Middle East Technical University, Mersin, Turkey. ${ }^{14}$ Department of Physicochemical Research, LEPL Alexandre Janelidze Institute of Geology, Tbilisi State University, Tbilisi, Georgia. ${ }^{15}$ Águas de Gaia EM, Vila Nova de Gaia, Portugal. ${ }^{16}$ State Oceanographic Institute, Moscow, Russia. ${ }^{17}$ Laboratory for Process Engineering, Environment, Biotechnology and Energy, Faculty of Engineering, University of Porto, Porto, Portugal. ${ }^{18}$ OIKOS - Associação de Defesa do Ambiente e do Património da Região de Leiria, Leiria, Portugal. ${ }^{19}$ Department of Environmental Technologies, International Campus of Excellence of the Sea, University of Cadiz, Puerto Real, Spain. ${ }^{20}$ Ukrainian Scientific Center of Ecology of the Sea, Odesa, Ukraine. ${ }^{21}$ National Antarctic Scientific Center of Ukraine, Kiev, Ukraine. ${ }^{22}$ Institute for Chemistry and Biology of the Marine Environment, Carl von Ossietzky University of Oldenburg, Wilhelmshaven, Germany. ${ }^{23}$ Department of Marine Chemistry and Biochemistry, Institute of Oceanology Polish Academy of Sciences, Sopot, Poland. ${ }^{24}$ Institute of Marine Sciences, National Research Council, Lerici, Italy. ${ }^{25}$ Department of Marine Science, University of Aegean, Lesbos, Greece. ${ }^{26}$ Present address: Laboratory of Biogeochemistry of Organic Contaminants, IFREMER, Nantes, France. ${ }^{27}$ Present address: Department of Ecological Chemistry, Helmholtz Center for Environmental Research - UFZ, Leipzig, Germany. ${ }^{28}$ Present address: Bund für Umwelt und Naturschutz Deutschland, Friends of the Earth Germany, Hannover, Germany. ${ }^{凶}$-mail: daniel.gonzalez@uca.es 
of plastic from rivers to the ocean at $0.47-2.75 \mathrm{Mt} \mathrm{yr}^{-1}$ globally. However, the datasets used to calculate riverine litter fluxes were built mostly from floating microlitter $(<5 \mathrm{~mm})$ and mesolitter $(0.5-2.5 \mathrm{~cm})$ counts $^{11-14}$, missing representative data from the macrolitter fraction $(>2.5 \mathrm{~cm})$. In particular, Lebreton et al ${ }^{11}$ and Schmidt et al. ${ }^{12}$ considered macroplastics as particles $>0.5 \mathrm{~cm}$, using average masses of 0.17 and $0.22 \mathrm{~g}$ per item, respectively, which are one or two orders of magnitude below the range of 5.4-10 g per item reported for riverine floating macroplastics ${ }^{15-17}$. From the estimations of marine floating plastic stock ${ }^{18}$, macrolitter is considered to represent a major portion of the plastic mass entering the ocean. Additionally, the estimates of plastic inputs to the ocean are closely linked to the uncertainties in the litter counts in rivers, which are still very limited in their spatial and temporal coverage ${ }^{14,19}$. In particular, field studies have highlighted the important temporal variability in plastic flux on seasonal and shorter timescales, often poorly covered by the existing data ${ }^{20-23}$.

Previous studies on global litter emissions from rivers into the ocean highlighted large rivers as the main contributors ${ }^{11,12}$. In addition, these rivers were mostly located in countries with high per capita MW generation rates as a result of not fully implemented practices of waste collection and management. Our focus in this study was on the input of floating macrolitter (FM) from Europe to the marine environment, considering modelled estimates from 32 European Union (EU) and neighbouring non-EU coastal countries with diverse economic status (lower-middle, upper-middle and high incomes). The European countries had a wide range of MW generation rates, from low (2\% MW) to moderately high (53\% MW), at a global scale ${ }^{10}$. The present analysis relied on harmonized data collection at the European scale, developed by a collaborative network of research institutions and non-governmental organizations (NGOs), and coordinated by the Directorate General Joint Research Centre (JRC) of the European Commission ${ }^{24}$. FM was monitored by visual observations in the period from June 2016 to September 2017. Visual counting was used to monitor floating items of visible size $(>2.5 \mathrm{~cm}$ in the largest extension), enabling only rough estimates of FM mass. The low cost and simplicity of the visual census facilitated monitoring on a large geographical scale with high frequency, for example, weekly, fortnightly or monthly, depending on the resource availability of each collaborator. Litter flux analyses included data collected in 42 rivers and streams from 11 countries, from 3 to 50 monitoring sessions per river. Additional comparable data were selected from the published literature ${ }^{17,25}$ in further analysis.

We used a harmonized approach to litter data collection and the determination of the most frequent FM items observed in rivers. This information was of relevance for several European regulatory and management frameworks, such as the Marine Strategy Framework Directive (MSFD) ${ }^{26}$, the Water Framework Directive (WFD) ${ }^{27}$, the European Strategy for Plastics in a Circular Economy ${ }^{1}$ and the Single-Use Plastic Directive ${ }^{28}$. Our repeated monitoring of FM flux (as items per hour) at fixed sites in different rivers and at different times has allowed us to provide a first reference for the variability and order of magnitude of the FM pollution level in European rivers. Finally, a regression model based on riverine FM observations and drainage basin characteristics (catchment area, population and $\mathrm{MW}$ ) has allowed us to obtain a large-scale estimate of the annual floating macrolitter loading (FML) from Europe into the ocean.

\section{Results}

We present here the riverine litter flux data for 42 rivers and streams across $11 \mathrm{EU}$ and non-EU countries. Empirical modelling of FML has allowed us to describe the spatial distribution of litter inputs from Europe to the ocean, including their distribution per country and for different drainage basin size ranges.

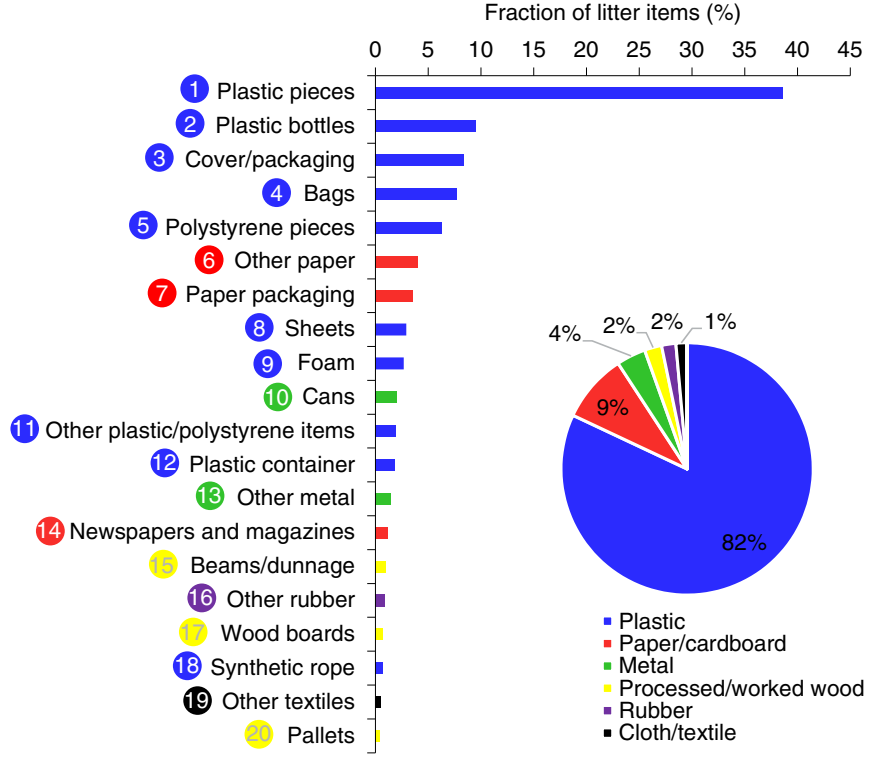

Fig. 1 | Top riverine FM litter items and materials in European rivers. Top riverine FM items and materials in European rivers shown as a fraction of the total.

Riverine litter flux and annual loading. In our European monitoring programme we sampled a total of 8,599 floating litter items, most of which were plastic items (82\%; Fig. 1$)$. These consisted predominantly of fragments from larger objects and single-use items, such as bottles, cover/packaging and bags. Non-plastic litter items corresponded mainly to paper/cardboard (9\%) and metal (4\%).

The FM flux was analysed in 42 rivers from 11 countries (Supplementary Data 1), counting at least one item in $72 \%$ of the 710 monitoring sessions considered. Individual FM flux values ranged broadly, spanning over five orders of magnitude, from 0.1 to 1,459 items $^{-1}$ (Fig. 2a). FM flux values and monitoring parameters, such as river width and observation track width, are available for each monitoring session in Supplementary Data 2. The FM flux variability within individual rivers frequently showed differences of two or three orders of magnitude, although some rivers reached up to four orders of magnitude. Annual FML ranged from $2 \times 10^{3}$ to $2 \times 10^{6}$ items $_{\mathrm{yr}^{-1}}$ when derived from the median, and from $7 \times 10^{3}$ to $3 \times 10^{6}$ items $\mathrm{yr}^{-1}$ when derived from the mean (Fig. 2b). In most rivers, the mean presented a higher annual loading than the median because of the influence of peak fluxes in their temporal variability. In general, despite differences among rivers, the FM flux and annual loading showed decreasing trends towards small basins.

Empirical modelling of FML. A regression analysis for MW $\left(\mathrm{t} \mathrm{yr}^{-1}\right)$ and FML (items $\mathrm{yr}^{-1}$ ) was performed on 41 drainage basins from 10 countries (Supplementary Data 3). The MW was calculated using a modification of the Jambeck et al. ${ }^{10}$ approach, intersecting data from geographic information system (GIS) layers of population density ${ }^{29}$ and river basin delimitation ${ }^{30}$. The database covered small streams to large European rivers, such as the Danube, Vistula, Douro and Rhône. The basin size ranged from 1 to $8 \times 10^{5} \mathrm{~km}^{2}$, the population from $1 \times 10^{3}$ to $8 \times 10^{7}$ inhabitants and the MW from $3 \times 10^{1}$ to $6 \times 10^{6} \mathrm{tyr}^{-1}$. The mean and median litter fluxes were used to explore the FML in each river. Although our monitoring programme of riverine FM is the most extensive to date, the number and distribution of monitoring sessions were still not sufficient to capture short-term pulses of FM linked to floods or heavy rainfall events. These FM pulses could be buffered in large river basins, but 
a
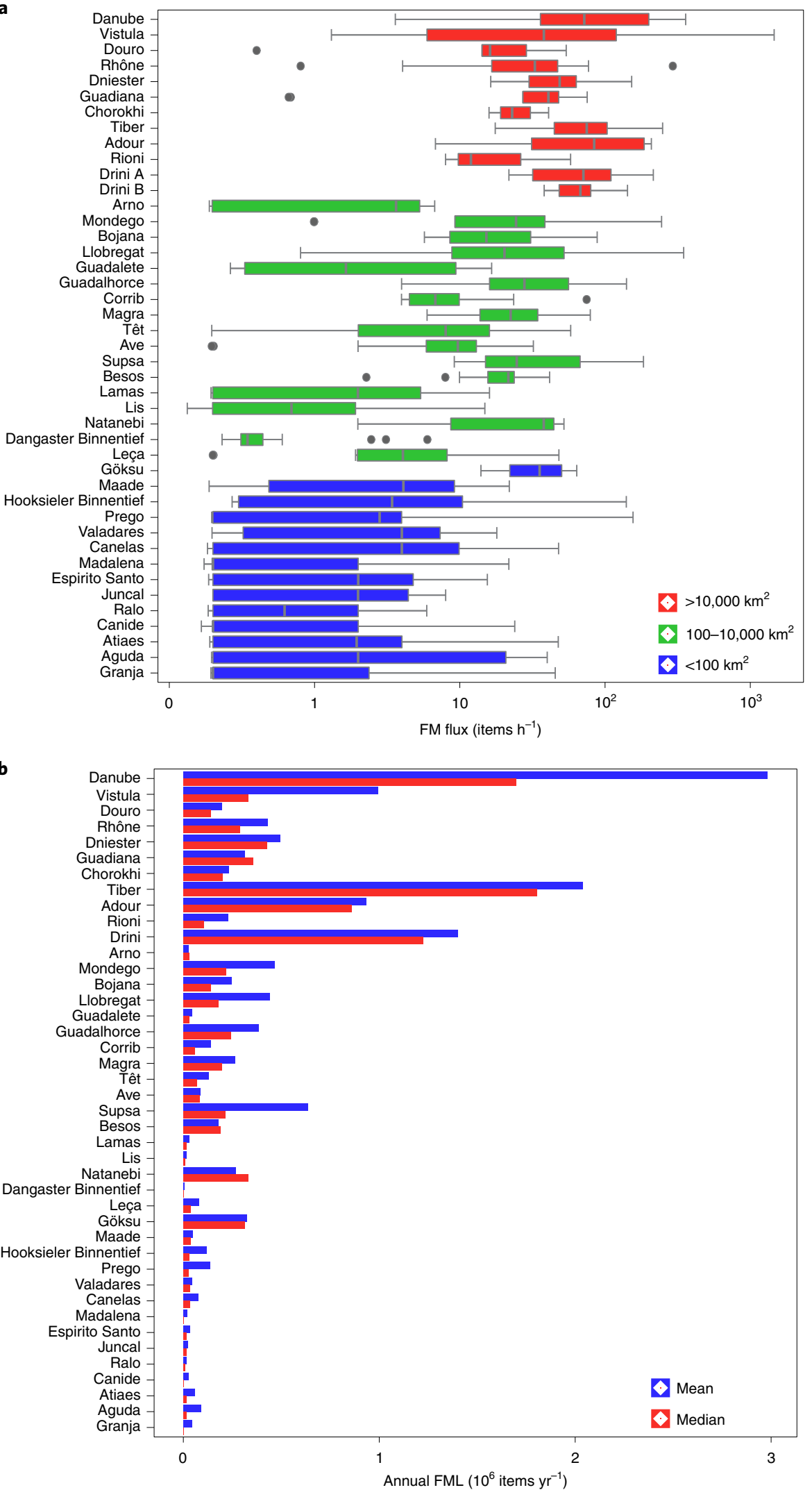

Fig. 2 | Floating macrolitter flux and annual loading in $\mathbf{4 2}$ rivers from 11 countries. a, FM flux in 42 rivers from 11 countries. The box-whisker plots present the 50th (median), 25th-75th (box), 10th-90th (whiskers) percentiles and outliers (grey circles). The colour code refers to river basin size. Fluxes are given for the two final distributaries of the Drini River (Drini A and Drini B); fluxes for the Danube River correspond to the Kiliya distributary, and for the Tiber River to the Fiumicino Canal. b. Annual FML in the 42 rivers from 11 countries. Extrapolations from mean- and median-based litter flux are presented. Note that the rivers are ranked in descending basin size. 
they can be intense and, particularly in small basins, can release large quantities of litter during a short period of time in flash-flood conditions $^{31}$. The mean-based FMLs account for the influence of potential high FM flux periods, whereas the median-based FMLs are representative of steadier FM flux over the long term, albeit likely underestimating FMLs.

In the optimization of the regression analysis between the MW generated inland and FML via rivers, we assessed the variability in the coefficient of determination $\left(R^{2}\right)$ in relation to the upstream distance of the river flow path from the basin outlet. $R^{2}$ improved with increasing distance, becoming asymptotic at approximately $450 \mathrm{~km}$ from the river outlet. This pattern was found for both mean- and median-based FMLs (Supplementary Fig. 1). In the median-based approach, the highest $R^{2}$ was reached at $450 \mathrm{~km}$, whereas in the mean-based regression, buffers greater than $450 \mathrm{~km}$ showed a minor increase, reaching the optimal $R^{2}$ at the whole basin scale. Therefore, in large river basins, the FM entering the ocean was mostly related to the amount of MW generated in the section of the basin extending $450 \mathrm{~km}$ upstream from the coast, following the river flow path. This corresponds to linear distances in the range of $200-300 \mathrm{~km}$, wider than the $50-\mathrm{km}$ linear strip used by Jambeck et al. ${ }^{10}$ to estimate total plastic inputs. Additionally, we found an inverse relationship (power-law regression: $R^{2}=0.63, n=41$ and $P<8 \times 10^{-10}$ ) between full basin size and the ratio of mean-based FML to MW in the basin $\left(\mathrm{FML} / \mathrm{MW}\right.$, in items $\left.\mathrm{t}^{-1}\right)$, revealing a decreasing litter transfer efficiency of MW to ocean towards larger river basins (Fig. 3a).

Using equation (1) in the Methods and the whole basin as the optimal area to calculate the MW per drainage basin, we obtained a statistically significant logarithmic linear regression model relating mean-based FML to MW ( $a=3.7837, b=0.3704, R^{2}=0.5634$ and $P<2 \times 10^{-10}$; Supplementary Fig. 2). Uncertainty was considered through a sensitivity analysis of the regression using 50 and $80 \%$ confidence intervals (Supplementary Table 1).

The calibrated model was used to estimate the FM inputs from 32,651 drainage basins $\left(>1 \mathrm{~km}^{2}\right)$ located in 32 European and Eurasian coastal countries (Fig. 4). The analysis revealed that $23 \%$ of the drainage basins were unpopulated $(n=7,401)$, releasing no litter into the ocean. The total number of FM items entering the ocean annually from Europe was estimated to be 626 million (80\% confidence interval: 307-925 million) in the mean-based model. The top five contributing countries contributed more than half of the European FML entering the ocean. Turkey presented the highest share $(16.8 \%)$, followed by Italy $(11.3 \%)$, the United Kingdom (8.4\%), Spain (8.21\%) and Greece (6.7\%; Fig. 5a). Several countries with the world's highest management rates $(>90 \%)$ were in the top positions of this ranking. High-management countries accounted for 401 million macrolitter items per year, sharing $64 \%$ of the European FML (Fig. 5b). The northern shore of the Mediterranean basin, deemed as one of the most plastic-polluted seas in the global ocean $^{32}$, received the highest FML from Europe (40.8\% of the total), followed by the North-East Atlantic Ocean (31.5\%), Black Sea (15.6\%) and Baltic Sea (12.1\%; Fig. 3 b and Fig. 5a).

\section{Discussion}

In this study we have developed the largest database on FM inputs from rivers to the ocean. The riverine FM fluxes were found to be highly variable, but have allowed, for the first time, the empirical calibration of the conversion rate of MW to marine macrolitter. Our modelled data contrast with the existing literature by highlighting the importance of FM input from small drainage basins compared with large rivers. Also, our results show that, in a geographical scenario such as Europe, the highest contribution of FML from Europe into the ocean, in the timeframe of our study, came from high-income countries.

Present and previous analyses of litter (plastic) emission from land ${ }^{11,12}$ were based on the approach developed by Jambeck et al. ${ }^{10}$.
This approach combined population density and economic status at country level (that is, gross national income, GNI) to estimate terrestrial MW, accounting for both inadequate waste management practices and littering. MW was used as the independent variable to infer waste inputs from land into the ocean. Constraints on the use of GNI-derived estimates arose from in-country differences in waste management or economic activity (for example, agricultural, industrial and urban areas). Moreover, litter was assumed to be $2 \%$ of the waste generated in each country, regardless of economic or lifestyle differences between countries. Lebreton and Andrady ${ }^{6}$ demonstrated, however, that moderate changes in the littering rates could lead to notable differences in waste emission. Finally, the transport of terrestrial MW to the ocean was modelled by determining the conversion rate of MW to marine debris, which should ideally be dependent on litter typology (micro and macro) and water surface run-off into the ocean ${ }^{12}$.

The empirical calibration of the conversion rate of MW to FM entering the ocean, covering a wide variety of drainage basins, economic status and waste management rates, appeared as a critical factor in addressing the limitations in the MW estimation described above. Here, we have demonstrated that visual counting of FM is a suitable large-scale monitoring strategy; and rivers, as conduits funnelling the collection and transport of MW, are shown as ideal sites to assess the transfer of terrestrial waste into the ocean.

The influence of river flow and rainfall on the transport of MW across basins $s^{21,23,25}$ raised the expectation of high variability in the observations. FM fluxes (items $\mathrm{h}^{-1}$ ) commonly varied by two to three orders of magnitude within each river (Fig. 2a). Furthermore, the mean FM flux generally showed higher values than the median flux (Fig. 2b). The mean was more affected by sporadic FM pulses, whereas the median was a steadier statistic. The coefficient of determination of the MW-FML regression model was higher for the median-based FML $\left(R^{2}=0.6738\right.$ and $\left.P<5 \times 10^{-11}\right)$ than for the mean-based FML $\left(R^{2}=0.5634\right.$ and $P<2 \times 10^{-8}$; Supplementary Table 1). However, the median-based approach likely underestimated the FM emissions because it disregarded the occasional

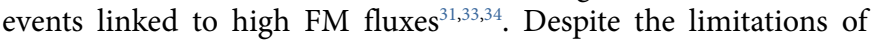
the monitoring approach, we found consistent agreement between theoretical MW and estimated FML across the wide range of basins monitored in Europe (Supplementary Fig. 2).

The projection of the empirical MW-FML regression model in European territory revealed the major FM sources to be along the coastline of the north-eastern Mediterranean, the Marmara Sea and the Black Sea (Fig. 4). These coastlines released waste from European and Eurasian countries with low $(<80 \%)$ to moderate (80-90\%) waste management rates, mainly Turkey, Ukraine, Russia and Georgia. The top sources (FML $>0.5 \times 10^{6}$ items $^{-1}{ }^{-1}$ ) in Eastern Europe corresponded to some of the largest European rivers (Danube, Dnieper, Southern Bug, Dniester and Don). In this region, major point sources $\left(\mathrm{FML}>0.5 \times 10^{6} \mathrm{items}^{-1} \mathrm{r}^{-1}\right)$ were not only attributed to medium and large rivers, but even to small basins $\left(<100 \mathrm{~km}^{2}\right)$ with high population densities (that is, the Istanbul metropolitan area). Small drainage basins, not necessarily associated with permanent rivers, supplied large loads when dense coastal population and low/medium management rates were combined. In countries with high waste-management rates $(>90 \%)$, small basins were never classified as relevant sources of pollution $\left(>0.25 \times 10^{6}\right.$ items $\left.\mathrm{yr}^{-1}\right)$. However, basins with annual loads above $0.1 \times 10^{6}$ items $\mathrm{yr}^{-1}$ were scattered throughout Western Europe. Additionally, the modelling of medium to large rivers in highly populated areas resulted in major point sources in Western Europe (Fig. 4).

Small-sized drainage basins $<100 \mathrm{~km}^{2}(n=30,331)$, and particularly those from 10 to $100 \mathrm{~km}^{2}(n=12,231)$, were responsible for the highest FML from Europe (Fig. 5b). The number of small-sized basins and high coastal population densities, combined with the 

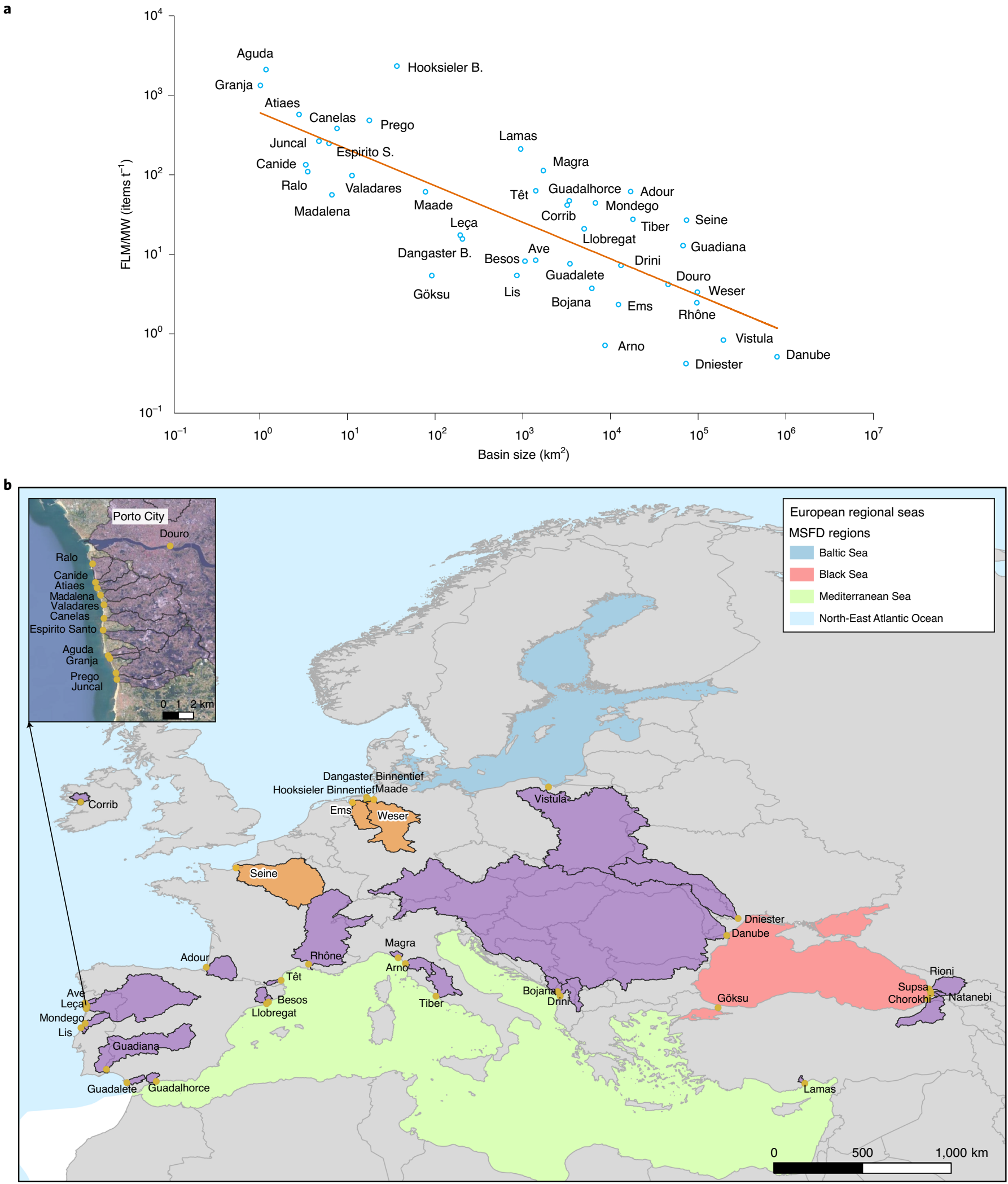

Fig. 3 | Litter transfer efficiency per river basin. a, Litter transfer efficiency for the mean-based FML showing the relationship between full basin size and the ratio of FML to $\mathrm{MW}$ in the basins monitored. The FML/MW ratio is indicative of the efficiency of $\mathrm{MW}$ surface loading into the ocean. The line shows the power-law regression $\left(R^{2}=0.63, n=41\right.$ and $\left.P<8 \times 10^{-10}\right)$. b. Observation sites and river basins monitored by the Riverine Litter Observation Network (RiLON). The river basins studied by RiLON are coloured in purple. Additional river basins considered in the study are coloured in orange. The limits of the European regional seas were extracted from the European Environment Agency dataset ${ }^{50}$. 


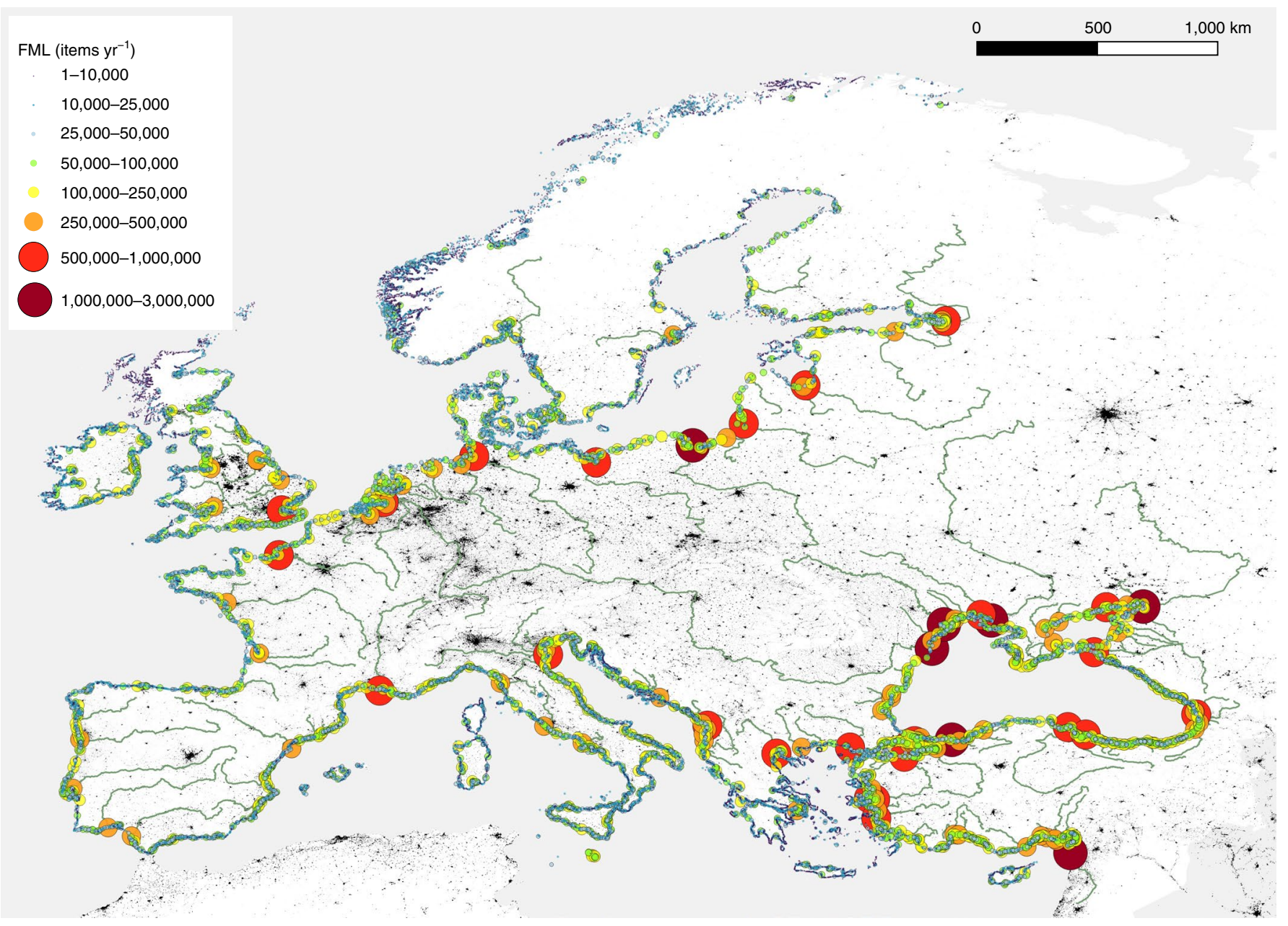

Fig. 4 | Spatial distribution of FML from Europe into the ocean. Spatial distribution of FML from Europe into the ocean based on mean-based modelled estimates. The coloured dots represent litter inputs predicted on the basis of the MW in each individual drainage basin.

increase in FM transfer efficiency towards the smallest basins (Fig. 3a), were the reasons for this result. Moreover, in the geographical coverage of our study, high-income countries contained $83 \%$ of the total basins and $76 \%$ of the small basins $\left(<100 \mathrm{~km}^{2}\right)$. Consequently, countries with high management rates but long and highly populated coastal areas (that is, Italy, the United Kingdom, Spain, France and Greece) were among the largest contributors to marine FM (Fig. 5a). Furthermore, high-income countries accounted for $64 \%$ of the European FML.

The frequency distribution of the FMLs from Europe increased towards the small-sized basins, except for the $1-10-\mathrm{km}^{2}$ basin size range, which have a limited capacity to host population, and therefore limited MW generation compared with the $10-100-\mathrm{km}^{2}$ basin size range (Fig. 5b). Overall, we estimated that most (71.3\%) of the FM items exported from Europe to the ocean were routed through small coastal basins $\left(<100 \mathrm{~km}^{2}\right)$. The sensitivity analysis of the regression confirmed similar results under different scenarios, that is, 70.5-71.9\% for the mean-based FML and 54.1-61.9\% for the median-based FML (Supplementary Table 1). This finding contrasts with previous assessments of the global riverine export of plastic litter from land to the ocean ${ }^{11,12}$ and theoretical model projections suggesting larger drainage basins as the main contributors ${ }^{6}$. Lebreton et al. ${ }^{11}$ found that the world's top 20 polluting rivers, mainly located in Asia, accounted for $67 \%$ of the total, whereas Schmidt et al. ${ }^{12}$ reported that the 10 top-ranked rivers transported $88-95 \%$ of the total, suggesting a low number of large rivers account for most of the global export. Our unprecedented results are mainly explained by the abundance of small drainage basins considered. We included in our computations all small basins (from 1 to $100 \mathrm{~km}^{2}$ ) draining into the ocean, whether they contained permanent river courses or not, whereas previous analyses predominantly focused on larger basins (Table 1). In fact, $93 \%$ of the basins in the present analysis were smaller than $100 \mathrm{~km}^{2}$, although they comprised only $10 \%$ of the total drainage area. Their elevated share in the total FML is primarily due to the high mean population density found in these small basins (217 inhabitants $\mathrm{km}^{-2}$ ) compared with the large ones ( 87 inhabitants $\mathrm{km}^{-2}$ ), reflecting the tendency of the human population to settle near shores $^{35}$. In addition, we found that MW is more efficiently transported to the ocean in small coastal basins than in large basins (Fig. 3a). Floating macro-items disposed in large basins are more likely to be retained by vegetation and other natural and artificial barriers (for example, river regulation structures such as dams), ballasted with sediments and epiphytes (being dragged down to deep river layers) or fragmented into small pieces before entering the ocean as meso- and microlitter, which were not computed in the FML fraction considered here. The role of dams in retaining and removing litter from the river basin could also be a relevant factor affecting this decreasing efficiency, because large rivers in Europe are mostly regulated ${ }^{36}$. A major example is the Danube River, whose drainage basin of $\sim 800,000 \mathrm{~km}^{2}$ runs through $14 \mathrm{EU}$ and non-EU countries and presents more than 700 large dams/ 


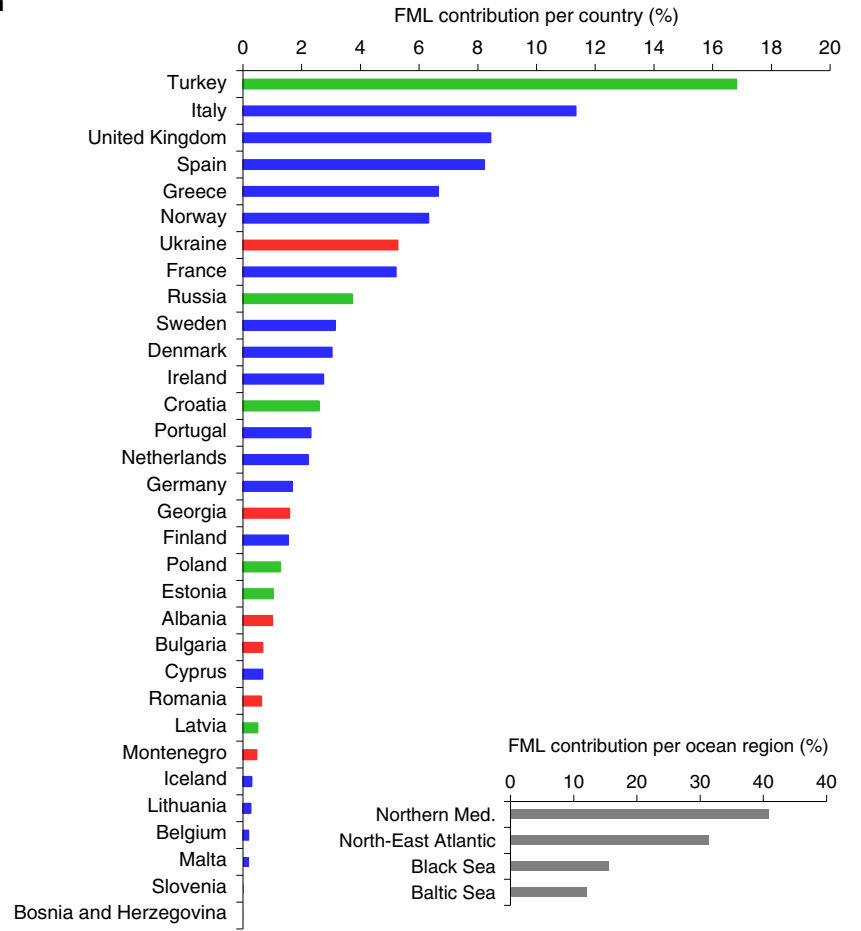

b

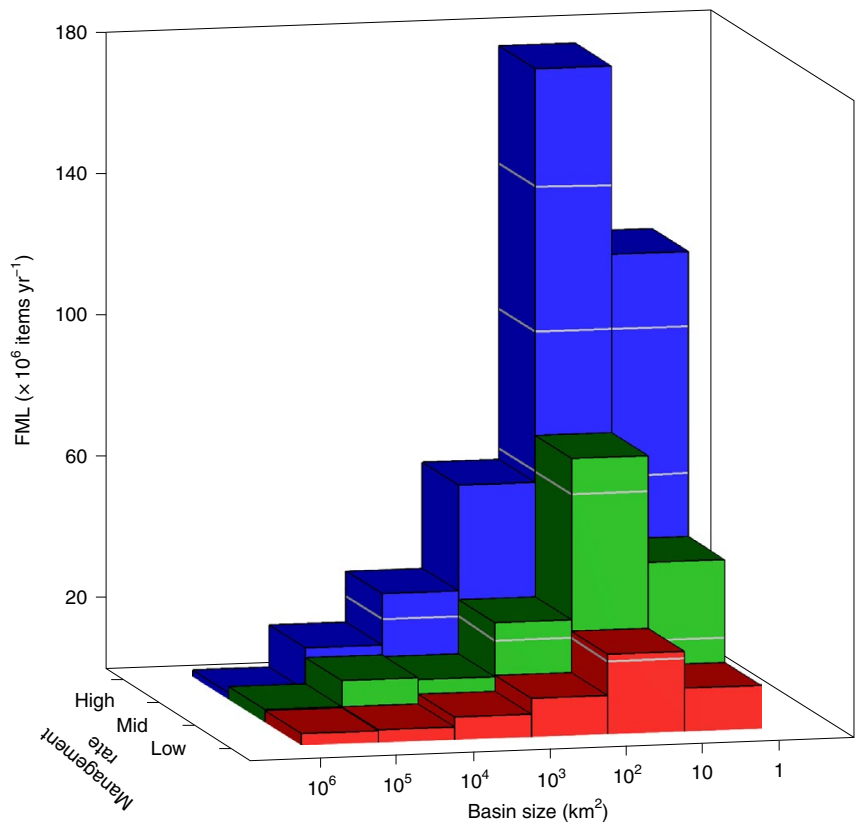

Fig. 5 | Distribution of FML per country, ocean region and drainage basin categories. a, Contribution per country and ocean region as a percentage of the total macrolitter released from Europe into the ocean based on mean-based modelled estimates. The data for the Mediterranean Sea only include input from European countries on the northern shore (Northern Med.). Inputs from transboundary basins are attributed to the country of the coastal outlet. b, Frequency distribution of the FML in relation to waste management rate and basin size based on mean-based modelled estimates. The waste management rates are defined as follows: high, >90\%; mid, 80-90\%; low, <80\%.

Table 1 | Global and European estimates of riverine plastic input

\begin{tabular}{|c|c|c|c|c|c|c|c|c|c|c|}
\hline \multirow[b]{2}{*}{$\begin{array}{l}\text { Geographical } \\
\text { coverage }\end{array}$} & \multirow[b]{2}{*}{$\begin{array}{l}\text { Modelling } \\
\text { studies }\end{array}$} & \multicolumn{4}{|c|}{ Experimental data in the model } & \multicolumn{5}{|c|}{ Model framework } \\
\hline & & $\begin{array}{l}\text { Number } \\
\text { of rivers }\end{array}$ & $\begin{array}{l}\text { Number } \\
\text { of } \\
\text { samples }\end{array}$ & $\begin{array}{l}\text { Basin area range } \\
\left(\mathrm{km}^{2}\right)\end{array}$ & $\begin{array}{l}\text { Number } \\
\text { of basins } \\
<100 \mathrm{~km}^{2}\end{array}$ & $\begin{array}{l}\text { Number } \\
\text { of basins }\end{array}$ & $\begin{array}{l}\text { Number } \\
\text { of basins } \\
<100 \mathrm{~km}^{2}\end{array}$ & $\begin{array}{l}\text { Average } \\
\text { mass per } \\
\text { microplastic } \\
(\mathrm{g})\end{array}$ & $\begin{array}{l}\text { Average } \\
\text { mass per } \\
\text { macroplastic } \\
(\mathrm{g})\end{array}$ & $\begin{array}{l}\text { Annual } \\
\text { loading } \\
\left(\mathrm{t} \mathrm{yr}^{-1}\right)\end{array}$ \\
\hline \multirow[t]{2}{*}{ Global } & $\begin{array}{l}\text { Lebreton } \\
\text { et al. }{ }^{11}\end{array}$ & 13 & 30 & $67-1.91 \times 10^{6}$ & 3 & 40,760 & 25,702 & 0.003 & 0.17 & $\begin{array}{l}1.15 \times 10^{6}- \\
2.41 \times 10^{6}\end{array}$ \\
\hline & $\begin{array}{l}\text { Schmidt } \\
\text { et al. }{ }^{12,39}\end{array}$ & 57 & 240 & $7-1.46 \times 10^{6}$ & 8 & 1,494 & 4 & 0.0018 & 0.22 & $\begin{array}{l}0.47 \times 10^{6}- \\
2.75 \times 10^{6}\end{array}$ \\
\hline \multirow[t]{3}{*}{ Europe $^{a}$} & $\begin{array}{l}\text { Lebreton } \\
\text { et al. }{ }^{11}\end{array}$ & 4 & 9 & $7.4 \times 10^{4}-8 \times 10^{5}$ & 0 & 5,370 & 3,659 & 0.003 & 0.17 & $\begin{array}{l}1,900- \\
7,400 \\
(3,100)^{b}\end{array}$ \\
\hline & $\begin{array}{l}\text { Schmidt } \\
\text { et al. }{ }^{12,39}\end{array}$ & 8 & 99 & $15-8 \times 10^{5}$ & 2 & 265 & 0 & 0.0018 & 0.22 & $\begin{array}{l}3,000- \\
11,000\end{array}$ \\
\hline & This work & 41 & 770 & $1-8 \times 10^{5}$ & 14 & 32,651 & 30,321 & n.a. & 5.4 & $\begin{array}{l}1,656-4,997 \\
(3,382)^{c}\end{array}$ \\
\hline
\end{tabular}

The table compares available annual estimates at global and European scales. Note that the previous estimates refer mainly to small-sized ( $<2.5 \mathrm{~cm}$ ) plastics with a low average mass per item, whereas the estimates presented here refer to a larger size of plastics $(>2.5 \mathrm{~cm})$ with considerably higher average mass. Our estimates should be deemed as loadings for a different plastic size interval. a Data extracted from existing modelling studies for the coastal domain considered in this study. ${ }^{b}$ Mid estimate. ${ }^{c}$ Mean-based estimate. n.a., not applicable.

weirs in its main tributaries ${ }^{37}$. However, information on dam functioning, reservoir levels, release mechanisms (for example, surface or bottom), coarse matter screening in hydropower plants, waste management and clean-up operations is limited and difficult to assess at large scale. Nevertheless, the diversity of rivers included in our model calibration (from small to large, from non-regulated to regulated) accounts implicitly for this variability factor.
In addition to the consideration of a wider range of basin sizes, the second main difference between previous models and the present one lies in the litter size analysed. Lebreton et al. ${ }^{11}$ and Schmidt et al. ${ }^{12}$ mostly dealt with microplastics $(<0.5 \mathrm{~cm})$, whereas we focused exclusively on FM items $(>2.5 \mathrm{~cm})$, providing loading estimates for litter sizes not accounted for previously. Currently, available measurements of long-term (seasonal or annual) FM flux are 
restricted to local studies in the Hilo River in Hawaii ${ }^{21}$, the Seine River in France ${ }^{38}$, the Saigon River in Vietnam ${ }^{15}$ and three rivers (Ems, Weser and Elbe) in Germany ${ }^{17}$. Carson et al. ${ }^{21}$ and Tramoy et al. ${ }^{38}$ reported FML in mass, which has prevented direct comparison with our data. In the rivers Saigon ${ }^{15}$ and Elbe ${ }^{17}$, the annual mid estimates (items $\mathrm{yr}^{-1}$ ) were up to two orders of magnitude higher than our mid estimates, whereas the rivers Ems and Weser ${ }^{17}$ showed annual mid estimates within half an order of magnitude of our mid estimates (Supplementary Fig. 3). Our regression model considered an annual mid estimate for the Seine River based on comparable plastic flux data from two different short monitoring periods ${ }^{25}$, which was approximately one order of magnitude above our model mid estimate (Supplementary Fig. 3). The differences between the studies are likely influenced by the diverse approaches used to estimate the annual loads, with the added complexity of assessing FM flux in waterways subject to tides ${ }^{15,17,25,38}$. By applying an average mass of $5.4 \mathrm{~g}$ per floating macroplastic item, extracted from field monitoring data in the Rhine River ${ }^{16}$, to the $82 \%$ fraction of plastic items counted in the RIMMEL (riverine and marine floating macrolitter monitoring and modelling of environmental loading) database (Fig. 1), the input of floating macroplastic from Europe into the ocean was estimated to be $3,382 \mathrm{tyr}^{-1}$ ( $80 \%$ confidence interval: 1,656-4,997 $\mathrm{t} \mathrm{yr}^{-1}$; Table 1). Considering all caveats and associated uncertainties, our estimate for macroplastic sizes $(>2.5 \mathrm{~cm})$ would represent a substantial mass in the total floating plastic released from land. It should be considered as an additional size fraction loading to the river plastic emission estimated by Lebreton et al. ${ }^{11}$ and Schmidt et al. ${ }^{12,39}$ for Europe, because those studies referred mainly to small-sized $(<2.5 \mathrm{~cm})$ and light-weight $(0.0018-0.22 \mathrm{~g})$ particles (Table 1).

Future research should provide larger datasets based on harmonized field data collection with an improved temporal resolution. Of equal importance is the need for new studies that include detailed metadata on river discharge and precipitation conditions prior to and during litter data collection. This would allow us to display the full variability of FM fluxes within a specific river, resulting in accurate estimates (number and mass) of annual and interannual variations. Ideally, additional monitoring methodologies should be put in place to obtain longer time-integrated samples, for example, the long-term deployment of nets or barriers. Unfortunately, these methods are subject to logistic and technical issues, for example, their efficiency in retaining items is unknown, leading to variable and uncertain results, particularly during extreme events such as heavy rains and floods ${ }^{21}$. New ground-breaking methodologies involving automated monitoring with cameras have been tested and could provide continuous measurements ${ }^{16,40,41}$ for better assessments in the near future. In any case, if regular monitoring programmes were to be implemented, riverine FM data could be a useful indicator for assessing the success or failure of prevention and mitigation measures, such as the banning of certain single-use plastic items ${ }^{28}$.

\section{Recommendations}

In this work we focused on the European continent, one of the regions with the highest economic status and expected waste management levels in the world ${ }^{10}$. Nonetheless, we estimated that between 307 and 925 million macrolitter items were leaked from Europe into the ocean annually. This estimate must be considered conservative, because neither subsurface inputs nor short-time emission pulses, linked to strong rainfall and flash-flood events, were considered. The distribution of FMLs in Europe highlights the contribution from small coastal basins $\left(<100 \mathrm{~km}^{2}\right)$, which was larger than those expected in previous analyses.

The large loading of FM leaked from high-income countries, supposedly with the best waste management rates, indicates that current efforts to control marine litter pollution remain insufficient. Besides improvements in waste management infrastructures and services, measures to reduce plastic consumption and avoid waste generation seem to be necessary to control plastic pollution in riverine and marine environments. It is also important to consider that a notable fraction of the plastic waste generated and recovered by high-income countries is shipped to emerging and developing countries to reduce pressure on their management systems, while compromising the health of ecosystems and people in recipient countries $^{42}$. Our results demonstrate the importance of regulating the unsustainable growth in plastic production and use $\mathrm{e}^{5,6}$, particularly plastic products with low recycling value. As waste streams remain far from being coupled to recovery and treatment systems in both low- and high-income countries, stricter international regulation, aimed at waste avoidance and valorization, is recommended to effectively address the relevant gaps within a short timeframe.

In conclusion, FM leaked from Europe into the ocean is an issue beyond large rivers and low-income countries. Our large-scale monitoring across a variety of river basins and countries has demonstrated the ability to provide reference values to evaluate the success of future prevention and mitigation measures in Europe, which could be particularly useful in the development of European regulations such as the MSFD ${ }^{26}$, the WFD ${ }^{27}$, the European Strategy for Plastics in a Circular Economy ${ }^{1}$ or the Single-Use Plastic Directive ${ }^{28}$.

\section{Methods}

In our analysis we used FM flux data collected in rivers across Europe to calibrate an empirical model relating MW generated in the drainage basins to the annual litter loading to the ocean.

Monitoring approach. The methodology used for data collection has been reported previously by González-Fernández and Hanke ${ }^{24}$. In brief, the harmonized monitoring approach, developed within the RIMMEL project and coordinated by the JRC, was based on four main elements: (1) visual observation as the monitoring method, (2) the JRC Floating Litter Monitoring application (app) as the tool for data collection and reporting, (3) the MSFD list of litter categories ${ }^{43}$ as the guideline for FM identification and (4) RiLON as the group of observers collecting data at a European scale.

Observations took place from an elevated position (bridge, pontoon, pier or riverside), identifying FM $(>2.5 \mathrm{~cm})$ flowing downstream in the respective river Observers performed monitoring sessions for 30-60 min. The monitoring set-up included three main parameters: river width (distance between the two margins of the river), observation track width (section or corridor of the river width that the observer scanned for floating items) and observation height (distance from the observer's sight to the water surface). The observation height allowed identification of items as small as $2.5 \mathrm{~cm}$, although binoculars could be used for confirmation. Although small rivers could be observed across their whole width, for larger rivers, the observation track width was limited to a fraction (Supplementary Data 1). The methodology allowed the observation of surface and near-surface floating items.

To harmonize data collection and reporting, the JRC provided a mobile computer application, the Floating Litter Monitoring app. The app used a list of FM items as agreed for the MSFD implementation in the Guidance on Monitoring of Marine Litter in the European Seas ${ }^{43}$. Observers introduced specific metadata and parameters for each monitoring session: observer's name, institution, river name, river flow speed, river width, observation track width, observation height, weather description and comments. Litter items were organized by material type and registered in the data file along with Global Positioning System coordinates, time and metadata. The data from each monitoring session were stored as individual datasets.

RiLON was formed to collectively acquire field data on FM in European rivers. The network is a group of scientific institutes, authorities, small- and medium-sized enterprises and NGOs, offering spatial coverage in $15 \mathrm{EU}$ and non-EU countries across the four European seas: Baltic Sea, Black Sea, Mediterranean Sea and North-East Atlantic Ocean (including the North Sea) ${ }^{44}$. Observation sites were selected in proximity to the river outlet to account for FM entering the sea. Data collection covered the period from June 2016 to September 2017. Observers were asked to perform weekly or fortnightly observations, delivering an individual dataset for each monitoring session. However, there were institutions that could not perform their regular monitoring for RIMMEL as planned, resulting in several rivers covered by only a few monitoring sessions (Supplementary Data 1 and 2).

RIMMEL database. The RIMMEL database compiled 817 monitoring sessions in 53 rivers and streams, with a total of $471 \mathrm{~h}$ of observation. All data were used in the identification of the top riverine floating macrolitter items (Fig. 1), as described by González-Fernández et al. ${ }^{44}$. To estimate litter flux, we discarded 
monitoring sessions with less than 15-min observation time from the analysis and rivers with less than three monitoring sessions as minimum selection criteria. Additionally, three rivers from the RIMMEL database had to be excluded in this step because their observation sites did not suit the purpose of analysing litter flux. This selection led to the consideration of 42 rivers, accounting for 710 monitoring sessions and $410 \mathrm{~h}$ of observation. Furthermore, only rivers with six or more valid monitoring sessions throughout the monitoring period were included in the regression model to obtain more representative litter flux variability for the annual loading estimates, resulting in 38 rivers with a total of 698 monitoring sessions and $398 \mathrm{~h}$ of observation (Supplementary Data 1). The spatial distribution of observation sites and river basins in the European regional seas is shown in Fig. 3b.

Litter flux calculation. Macrolitter flux was calculated for each monitoring session, dividing the number of observed anthropogenic items by observation time and track width (items $\mathrm{h}^{-1} \mathrm{~m}^{-1}$ ). This flux was extrapolated to the total river width by assuming equal distribution for the whole river cross-section ${ }^{17,22,23,45}$, providing litter flux estimates as items per hour (items $\mathrm{h}^{-1}$; Supplementary Data 2). In the case of individual monitoring sessions with zero litter counts (no items observed during the session time), a minimum litter flux was calculated to replace the values of zero $\left(0\right.$ items $\left.\mathrm{h}^{-1}\right)$, enabling their computation in the logarithmic scale. This minimum litter flux value was calculated as one order of magnitude lower than the detection limit (estimated as one item divided by the duration of the individual monitoring session, and divided again by ten) to ensure a conservative result below the mean and median litter flux calculated for the specific river. Observations in estuaries under tidal influence (60 monitoring sessions from 5 rivers) were collected during outflow or low-tide conditions and resulted in flux estimates within the order of magnitude found in other rivers with similar basin descriptive variables in the database. Therefore, there was no further consideration of tidal influence.

Finally, annual FMLs were derived from the mean and median litter fluxes (items $\mathrm{h}^{-1}$ ) obtained in each river from their corresponding set of monitoring sessions: items $\mathrm{h}^{-1} \times 24 \mathrm{~h} \times 365 \mathrm{~d}=$ items $^{-1} \mathrm{r}^{-1}$. The number of monitoring sessions per river used to derive the mean and median ranged from 3 to 50 (Supplementary Data 1). The Drini River (draining into the Mediterranean Sea in Albania, see Fig. 3b) was monitored at its two final distributaries (Drin A and Drini B), thus the annual loads were calculated by the addition of their respective mean and median fluxes. When monitoring was performed in a main distributary at the river outlet, annual loads were extrapolated considering the relative width proportion of the whole river stream surface at the corresponding upstream bifurcation. This was repeated for the Danube River, monitored at the northern distributary (Kiliya), draining into the Black Sea at the border between Romania and Ukraine after its upstream bifurcation at $45.229657^{\circ} \mathrm{N}, 28.737420^{\circ}$ $\mathrm{E}$, and for the Tiber River, monitored at the Fiumicino Canal, draining into the Mediterranean Sea after its upstream bifurcation at $41.776219^{\circ} \mathrm{N}, 12.278267^{\circ} \mathrm{E}$ (Supplementary Data 3).

Drainage basin descriptive variables. Catchment area, population and MW generation were used to describe the studied drainage basins. We obtained data on catchment area and number of inhabitants per country upstream from each drainage basin using QGIS (www.qgis.org) and the catchment data from the Catchment Characterisation Model river and catchment database $\mathrm{e}^{30}$ and the European Catchments and Rivers Network System (ECRINS) database ${ }^{46}$, the population data from the Global Human Settlement Population Grid (2015 residential population estimates, $250 \mathrm{~m}$ resolution $)^{29}$ and country boundaries from Natural Earth ${ }^{47}$ (see Supplementary Methods for the delimitation of small drainage basins). From the World Bank's study on per capita waste generation rates per country ${ }^{48}, \mathrm{MW}$ generation rates per country (in $\mathrm{kg}_{\text {person }}{ }^{-1} \mathrm{yr}^{-1}$ ) were estimated sensu Jambeck et al. ${ }^{10}$ and Schmidt et al. ${ }^{12}$ (Supplementary Data 4) and used to obtain annual MW per drainage basin $\left(\mathrm{tyr}^{-1}\right)$.

Calibration and application of the empirical model. The FML (items $\mathrm{yr}^{-1}$ ) was related to the MW $\left(\mathrm{t} \mathrm{yr}^{-1}\right)$ generated in the studied drainage basins to assess litter input to the ocean. This calibration was based on the annual FML derived from the mean litter flux extrapolation. The 38 rivers selected from the RIMMEL database (minimum six monitoring sessions per river) were complemented with three additional rivers offering comparable data from the literature. The macrolitter loadings from the rivers Ems and Weser rivers in Germany ${ }^{17}$ and the Seine River in France ${ }^{25}$ were included in the regression model, improving the geographical coverage in highly populated areas of North-Western Europe (Fig. $3 \mathrm{~b}$ and Supplementary Data 3). For the rivers Ems and Weser, annual mid estimates of FM input to the sea were calculated based on the low and high daily estimates of macrolitter emission data of Schöneich-Argent et al. ${ }^{17}$; for the Seine River, a mean litter flux estimate was calculated for the two monitoring periods examined by van Emmerik et al. ${ }^{25}$ and extrapolated to annual loading (items $\mathrm{h}^{-1} \times 24 \mathrm{~h} \times 365 \mathrm{~d}$ ); further details regarding additional comparable data in the regression model are available in the Supplementary Methods.

The data were log-transformed to perform a linear least-squares regression:

$$
\log _{10}(\mathrm{FML})=a+b \log _{10}(\mathrm{MW})
$$

where $a$ and $b$ are the intercept and slope, respectively. We adopted the hypothesis that, in large rivers, FM generated far upstream may not reach the sea as such, but it may change its buoyancy (for example, a plastic bottle will sink when the air trapped inside is replaced by water) or fragment into smaller pieces (for example, through the weathering of plastic bags attached to vegetation on river banks), and therefore become unobservable/out of range of the FM monitoring. Because the effective extent of the area used for the calculation of MW contributing to FML may not cover the entire basin, we optimized the coefficient of determination $\left(R^{2}\right)$ for equation (1). We selected upstream flow distance buffers with increasing length from the river outlet to delimit the overlapping basin section, based on river channel network and functional elementary catchments from the ECRINS database $^{46}$ (Supplementary Fig. 1). The MW was then calculated for each distance buffer. This optimization was intended to improve the correspondence between MW and FML via rivers, rather than considering the whole river basin for the large rivers. The regression analysis was tested for each distance buffer for the whole set of rivers, identifying $450 \mathrm{~km}$ as the best fit for the median-based extrapolation. This optimization was also explored for the mean-based extrapolation, and although $R^{2}$ was mostly stabilized at $450 \mathrm{~km}$, there was a minor increase towards larger buffers and, therefore, the whole basin was considered in this case (Supplementary Fig. 1).

To upscale our estimates at the European level, the most effective extent of the drainage basin was used to estimate the population and MW to predict the FML for each individual drainage basin $\left(>1 \mathrm{~km}^{2}\right)$ in Europe. Although the majority of the drainage basins were fully contained within the $450 \mathrm{~km}$ upstream flow distance buffer, the rivers with large extension and/or transboundary drainage basins $(n=93)$ were processed separately to ensure the correct application of country-referenced distance buffers (see the graphical example for the Iberian Peninsula in Supplementary Fig. 4). A total of 32,651 basins were analysed in the present study. For the geographical visualization of the results, we considered sea outlets $(n=17,772)$ extracted from the ECRINS database ${ }^{46}$; the centroids of polygons were plotted for drainage basins with undefined sea outlet nodes.

A sensitivity analysis was performed to consider the uncertainties related to the use of the mean- and median-based litter flux extrapolations in the model. The percentile bootstrap method ${ }^{49}(10,000$ replicates, random sampling with replacement) was applied to calculate two confidence intervals (CIs), 50\% CI (25th and 75 th percentiles) and $80 \% \mathrm{CI}$ (10th and 90th percentiles), for the mean and median litter flux in each river (Supplementary Data 3). The confidence intervals were extrapolated to annual load (items $\mathrm{yr}^{-1}$ ) and tested in the regression analysis under each scenario (Supplementary Table 1). In the case of the rivers Ems, Weser and Seine, low and high estimates from the literature ${ }^{17,25}$ were selected to be used in the 50 and $80 \%$ CI analysis (see Supplementary Methods for additional comparable data in the regression model).

Reporting Summary. Further information on research design is available in the Nature Research Reporting Summary linked to this article.

\section{Data availability}

The data that support the findings of this study are available at https:// marinelitterlab.eu/ and from the corresponding author upon request. Datasets include a GIS shapefile for the estimates of 'annual floating macrolitter loading' (FML) obtained in the modelling output.

Received: 22 May 2020; Accepted: 15 April 2021; Published online: 10 June 2021

\section{References}

1. Communication from the Commission to the European Parliament, the Council, the European Economic and Social Commitee and the Committee of the Regions. A European Strategy for Plastics in a Circular Economy (European Commission, 2018).

2. GESAMP Sources, Fate and Effects of Microplastics in the Marine Environment: Part 2 of a Global Assessment (eds Kershaw, P. J. et al.) (International Maritime Organization, 2016).

3. NOAA NOAA Marine Debris Program, Strategic Plan 2016 - 2020 (US Department of Commerce, National Oceanic and Atmospheric Administration, National Ocean Service, Office of Response and Restoration, Marine Debris Division, 2015); https://marinedebris.noaa.gov/

4. Marine Plastic Debris and Microplastics: Global Lessons and Research to Inspire Action and Guide Policy Change (United Nations Environment Programme, 2016).

5. Geyer, R., Jambeck, J. R. \& Law, K. L. Production, uses, and fate of all plastics ever made. Sci. Adv. 3, e1700782 (2017).

6. Lebreton, L. \& Andrady, A. Future scenarios of global plastic waste generation and disposal. Palgrave Commun. 5, 6 (2019).

7. Lau, W. W. Y. et al. Evaluating scenarios toward zero plastic pollution. Science 369, 1455-1461 (2020).

8. Rillig, M. C. \& Lehmann, A. Microplastic in terrestrial ecosystems. Science 368, 1430-1431 (2020). 
9. Huerta Lwanga, E. et al. Field evidence for transfer of plastic debris along a terrestrial food chain. Sci. Rep. 7, 14071 (2017).

10. Jambeck, J. R. et al. Plastic waste inputs from lansd into the ocean. Science 347, 768-771 (2015).

11. Lebreton, L. C. M. et al. River plastic emissions to the world's oceans. Nat. Commun. 8, 15611 (2017).

12. Schmidt, C., Krauth, T. \& Wagner, S. Export of plastic debris by rivers into the sea. Environ. Sci. Technol. 51, 12246-12253 (2017).

13. Dris, R. et al. Beyond the ocean: contamination of freshwater ecosystems with (micro-)plastic particles. Environ. Chem. 12, 539-550 (2015).

14. Breuninger, E. et al. Plastics in European freshwater environments. In Conference on Plastics in Freshwater Environments (eds Bänsch-Baltruschat, B. et al.) 16-71 (Umweltbundesamt, 2017).

15. van Emmerik, T., Strady, E., Kieu-Le, T.-C., Nguyen, L. \& Gratiot, N. Seasonality of riverine macroplastic transport. Sci. Rep. 9, 13549 (2019).

16. Vriend, P. et al. Rapid assessment of floating macroplastic transport in the Rhine. Front. Mar. Sci. 7, 10 (2020)

17. Schöneich-Argent, R. I., Dau, K. \& Freund, H. Wasting the North Sea? - A field-based assessment of anthropogenic macrolitter loads and emission rates of three German tributaries. Environ. Pollut. 263, 114367 (2020).

18. Eriksen, M. et al. Plastic pollution in the world's oceans: more than 5 trillion plastic pieces weighing over 250,000 tons afloat at sea. PLOS ONE 9, e111913 (2014).

19. González, D. et al. Riverine Litter Monitoring - Options and Recommendations (Joint Research Centre, European Commission, 2016); https://doi. org/10.2788/461233

20. Moore, C. J., Lattin, G. L. \& Zellers, A. F. Quantity and type of plastic debris flowing from two urban rivers to coastal waters and beaches of Southern California. Rev. Gest. Cost. Integr. 11, 65-73 (2011).

21. Carson, H. S. et al. Tracking the sources and sinks of local marine debris in Hawaii. Mar. Environ. Res. 84, 76-83 (2013).

22. Crosti, R., Arcangeli, A., Campana, I., Paraboschi, M. \& González-Fernández, Z 'Down to the river': amount, composition, and economic sector of litter entering the marine compartment, through the Tiber river in the Western Mediterranean Sea. Rend. Lincei Sc. Fis. Nat. 29, 859-866 (2018).

23. Castro-Jiménez, J., González-Fernández, D., Fornier, M., Schmidt, N. \& Sempéré, R. Macro-litter in surface waters from the Rhone River: plastic pollution and loading to the NW Mediterranean Sea. Mar. Pollut. Bull. 146, 60-66 (2019)

24. González-Fernández, D. \& Hanke, G. Toward a harmonized approach for monitoring of riverine floating macro litter inputs to the marine environment. Front. Mar. Sci. 4, 86 (2017).

25. van Emmerik, T. et al. Seine plastic debris transport tenfolded during increased river discharge. Front. Mar. Sci. 6, 642 (2019).

26. Directive 2008/56/EC of the European Parliament and of the Council of 17 June 2008 Establishing a Framework for Community Action in the Field of Marine Environmental Policy (Marine Strategy Framework Directive) (European Commission, 2008).

27. Directive 2000/60/EC of the European Parliament and of the Council of 23 October 2000 Establishing a Framework for Community Action in the Field of Water Policy (European Commission, 2000).

28. Directive (EU) 2019/904 on the Reduction of the Impact of Certain Plastic Products on the Environment (European Commission, 2019).

29. European Commission, Joint Research Centre, Columbia University \& CIESIN GHS population grid, derived from GPW4, multitemporal $(1975,1990$, 2000, 2015) (Joint Research Centre, European Commission, 2015); http:// data.europa.eu/89h/jrc-ghsl-ghs_pop_gpw4_globe_r2015a

30. De Jager, A. \& Vogt, J. Rivers and Catchments of Europe - Catchment Characterisation Model (CCM) (Joint Research Centre, European Commission, 2007); http://data.europa.eu/89h/ fe1878e8-7541-4c66-8453-afdae7469221

31. Pierdomenico, M., Casalbore, D. \& Chiocci, F. L. Massive benthic litter funnelled to deep sea by flash-flood generated hyperpycnal flows. Sci. Rep. 9, 5330 (2019).

32. Cózar, A. et al. Plastic accumulation in the Mediterranean Sea. PLoS ONE 10, e0121762 (2015)

33. Hurley, R., Woodward, J. \& Rothwell, J. J. Microplastic contamination of river beds significantly reduced by catchment-wide flooding. Nat. Geosci. 11, 251-257 (2018).

34. Axelsson, C. \& van Sebille, E. Prevention through policy: urban macroplastic leakages to the marine environment during extreme rainfall events. Mar. Pollut. Bull. 124, 211-227 (2017).
35. Small, C. \& Nicholls, R. J. A global analysis of human settlement in coastal zones. J. Coast. Res. 19, 584-599 (2003).

36. Grill, G. et al. Mapping the world's free-flowing rivers. Nature 569, 215-221 (2019).

37. Danube River Basin District: Part A - Basin-Wide Overview (ICPDR, 2005): https://www.icpdr.org/main/sites/default/files/nodes/documents/danube basin_analysis_2004.pdf

38. Tramoy, R. et al. Assessment of the plastic inputs from the Seine basin to the sea using statistical and field approaches. Front. Mar. Sci. 6, 151 (2019).

39. Schmidt, C., Krauth, T. \& Wagner, S. Correction to export of plastic debris by rivers into the sea. Environ. Sci. Technol. 52, 927 (2018).

40. Kataoka, T. \& Nihei, Y. Quantification of floating riverine macro-debris transport using an image processing approach. Sci. Rep. 10, 2198 (2020).

41. Lieshout, C., Oeveren, K., Emmerik, T. \& Postma, E. Automated river plastic monitoring using deep learning and cameras. Earth Space Sci. 7, e2019EA000960 (2020).

42. Brooks, A. L., Wang, S. \& Jambeck, J. R. The Chinese import ban and its impact on global plastic waste trade. Sci. Adv. 4, 131 (2018).

43. Galgani, F. et al. Guidance on Monitoring of Marine Litter in European Seas (Joint Research Centre, European Commission, 2013); https://doi. org/10.2788/99475

44. González-Fernández, D., Hanke, G. \& RiLON Floating Macro Litter in European Rivers - Top Items (European Commission, 2018); https://doi. org/10.2760/316058

45. Schirinzi, G. F. et al. Riverine anthropogenic litter load to the Mediterranean Sea near the metropolitan area of Barcelona, Spain. Sci. Total Environ. 714, 136807 (2020).

46. European Catchments and Rivers Network System (Ecrins) (European Environment Agency, 2012); https://www.eea.europa.eu/data-and-maps/data/ european-catchments-and-rivers-network

47. Country Boundaries. Admin 0 - Countries v4.1.0 (Natural Earth, 2021); www.naturalearthdata.com

48. Hoornweg, D. \& Bhada-Tata, P. What a Waste: A Global Review of Solid Waste Management (World Bank Group, 2012); http://hdl.handle. net/10986/17388

49. Davison, A. C. \& Hinkley, D. V. Bootstrap Methods and their Application (Cambridge Univ. Press, 1997); https://doi.org/10.1017/CBO9780511802843

50. Europe Seas (European Environment Agency, 2021); https://www.eea.europa. eu/data-and-maps/data/europe-seas-1

\section{Acknowledgements}

We acknowledge the additional members (coordinators and observers) of RiLON, listed in Supplementary Data 5, for their support in the field data collection and feedback during the data quality control. D.G.-F. was supported by the JRC institutional exploratory project RIMMEL (272346), PLASTREND (BBVA Foundation) and the European Union (H2020-MSCA-IF-2018 846843 - LitRivus). J.V. and C.M.-C. were supported by the MIDaS project (Spanish Ministry of Science, Innovation and Universities, CTM2016-77106-R, AEI/FEDER/UE).

\section{Author contributions}

D.G.-F., A.C. and G.H. conceived and drafted the present study; they contributed equally to the work. D.G.-F., A.C., J.V. and C.M.-C. analysed the data and prepared the results. The rest of the authors coordinated and participated in the field data collection and commented on the data quality assessment for the RIMMEL database. All authors read and commented on the manuscript.

\section{Competing interests}

The authors declare no competing interests.

\section{Additional information}

Supplementary information The online version contains supplementary material available at https://doi.org/10.1038/s41893-021-00722-6.

Correspondence and requests for materials should be addressed to D.G.-F.

Peer review information Nature Sustainability thanks the anonymous reviewers for their contribution to the peer review of this work.

Reprints and permissions information is available at www.nature.com/reprints.

Publisher's note Springer Nature remains neutral with regard to jurisdictional claims in published maps and institutional affiliations.

(c) The Author(s), under exclusive licence to Springer Nature Limited 2021 


\section{Reporting Summary}

Nature Research wishes to improve the reproducibility of the work that we publish. This form provides structure for consistency and transparency in reporting. For further information on Nature Research policies, see our Editorial Policies and the Editorial Policy Checklist.

\section{Statistics}

For all statistical analyses, confirm that the following items are present in the figure legend, table legend, main text, or Methods section.

n/a Confirmed

$\square \bigotimes$ The exact sample size $(n)$ for each experimental group/condition, given as a discrete number and unit of measurement

Х $\square$ A statement on whether measurements were taken from distinct samples or whether the same sample was measured repeatedly

$\square$ The statistical test(s) used AND whether they are one- or two-sided

$\square$ Only common tests should be described solely by name; describe more complex techniques in the Methods section.

Х A description of all covariates tested

$\square$ \ A description of any assumptions or corrections, such as tests of normality and adjustment for multiple comparisons

$\square$ A full description of the statistical parameters including central tendency (e.g. means) or other basic estimates (e.g. regression coefficient)

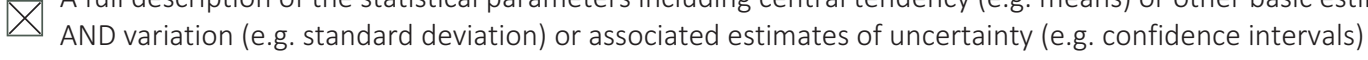

$\square$ For null hypothesis testing, the test statistic (e.g. $F, t, r$ ) with confidence intervals, effect sizes, degrees of freedom and $P$ value noted

Give $P$ values as exact values whenever suitable.

Х $\square$ For Bayesian analysis, information on the choice of priors and Markov chain Monte Carlo settings

Х $\square$ For hierarchical and complex designs, identification of the appropriate level for tests and full reporting of outcomes

$\bigotimes \square$ Estimates of effect sizes (e.g. Cohen's $d$, Pearson's $r$ ), indicating how they were calculated

Our web collection on statistics for biologists contains articles on many of the points above.

\section{Software and code}

Policy information about availability of computer code

Data collection SQL Server 2014 Management Studio, QGIS 3.4 and Microsoft Excel 2010 were used to obtain and organize the data.

Field data was collected and reported using a non-published mobile computer application, the JRC Floating Litter Monitoring app, developed by the Joint Research Centre of the European Commission. This app is currently being updated to produce a public version. The software version we used to collect the field data included in this manuscript is not available since the end of the RIMMEL project in 2017. The corresponding author can provide access to this non-published version of the software via a personal Dropbox link.

Data analysis This study was conducted using basic packages of QGIS 3.4, Microsoft Excel 2010 and R 3.6.1.

For manuscripts utilizing custom algorithms or software that are central to the research but not yet described in published literature, software must be made available to editors and reviewers. We strongly encourage code deposition in a community repository (e.g. GitHub). See the Nature Research guidelines for submitting code \& software for further information.

\section{Data}

Policy information about availability of data

All manuscripts must include a data availability statement. This statement should provide the following information, where applicable:

- Accession codes, unique identifiers, or web links for publicly available datasets

- A list of figures that have associated raw data

- A description of any restrictions on data availability

The data that support the findings of this study are available at https://marinelitterlab.eu/ and from the corresponding author upon request. Datasets include a GIS shapefile for the estimates of 'annual Floating Macro-litter Loading' (FML) obtained in the modelling output. 


\section{Field-specific reporting}

Please select the one below that is the best fit for your research. If you are not sure, read the appropriate sections before making your selection.

Life sciences

Behavioural \& social sciences

Ecological, evolutionary \& environmental sciences

For a reference copy of the document with all sections, see nature.com/documents/nr-reporting-summary-flat.pdf

\section{Ecological, evolutionary \& environmental sciences study design}

All studies must disclose on these points even when the disclosure is negative.

Study description

In this study we present the most comprehensive results on floating macro-litter input from rivers to the marine environment across Europe. We analyze litter flux data to determine variability within rivers and to develop a regression model that allows up-scaling Floating macro litter annual loading for all rivers at European scale. Data was collected using a harmonized monitoring approach facilitating reproducibility and comparison at large spatial scale. Our results set a baseline for future research and monitoring under regulatory frameworks on plastic pollution.

Research sample

The RIMMEL database compiled 817 monitoring sessions in 53 rivers across 15 European and Eurasian countries, comprising a total of 471 hours of visual observation.

Sampling strategy

A harmonized approach was used for data collection. The method consisted of stationary-point visual observations on surface riverine waters by using a mobile computer application to collect data for quantification of floating litter fluxes. The monitoring network was built on a collaborative action including Scientific Institutes, Authorities, SMEs and NGOs, which collected data according to their availability of resources.

Data collection

The data collection was managed by the co-authors. The observers used the mobile computer application 'JRC Floating Litter Monitoring app' for a harmonized data collection and reporting.

Timing and spatial scale Data collection started in September 2016 and finished in September 2017. Observers were asked to perform weekly or fortnightly observations, delivering an individual dataset for each monitoring session. However, there were institutions that could not perform their regular monitoring for RIMMEL as planned, resulting in several rivers covered by only few monitoring sessions. Spatial coverage in 15 EU and non-EU countries across the four European seas: Baltic Sea, Black Sea, Mediterranean Sea and North-East Atlantic Ocean (including the North Sea).

Data exclusions

Some rivers from the RIMMEL database were excluded prior to analysis because the monitoring set up did not fit the scope of quantifying litter flux input to the sea. To estimate litter flux, we selected 42 rivers, accounting for 710 monitoring sessions and 410 hours of observation. Further, only rivers with six or more valid monitoring sessions throughout the year were included in the regression model, resulting in 38 rivers with a total of 698 monitoring sessions and 398 hours of observation. Selected rivers and monitoring sessions are available in Supplementary Data 2. The spatial distribution of observation sites and river basins in the European Regional Seas are shown in Supplementary Fig. 1.

Reproducibility

The use of a harmonized approach for data collection and reporting allows performing a repetitive monitoring procedure to obtain field data for calculation of litter flux and annual loading based on mean and median values per river.

The reproducibility of the analysis depend on the variability of litter quantities found during the actual monitoring sessions in the rivers and the amount of datasets collected per river to calculate litter flux mean and median values.

Our litter flux analysis and regression model allow comparing future monitoring results for reproducibility and trend analysis purposes.

Randomization

Our study was based on available field data (riverine floating macro litter flux) collected by a monitoring network (a collaborative action) in rivers at European scale. The classification of litter items used a list of floating macro-litter items as agreed for the MSFD implementation in the 'Guidance on Monitoring of Marine Litter in the European Seas'. (MSFD stands for Marine Strategy Framework Directive, 2008/56/EC)

Blinding

Our study was based on available field data (riverine floating macro litter flux) collected by a monitoring network (a collaborative action) in rivers at European scale, and therefore blinding is not relevant.

Did the study involve field work? \ Yes $\square$ No

\section{Field work, collection and transport}

Field conditions

Field conditions were variable do to the different sampling locations across Europe and the timing of data collection, mainly weekly and fortnightly observations during 13 months. 


\section{Reporting for specific materials, systems and methods}

We require information from authors about some types of materials, experimental systems and methods used in many studies. Here, indicate whether each material, system or method listed is relevant to your study. If you are not sure if a list item applies to your research, read the appropriate section before selecting a response.

\section{Materials \& experimental systems}

\begin{tabular}{|c|c|}
\hline $\mathrm{n} / \mathrm{a}$ & Involved in the study \\
\hline$\Delta$ & $\square$ Antibodies \\
\hline Х & Eukaryotic cell lines \\
\hline$\bigotimes$ & $\square$ Palaeontology and archaeology \\
\hline Х & $\square$ Animals and other organisms \\
\hline 区 & $\square$ Human research participants \\
\hline$\longrightarrow$ & $\square$ Clinical data \\
\hline 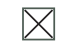 & Dual use research of concern \\
\hline
\end{tabular}

\section{Methods}

\begin{tabular}{l|l} 
n/a & Involved in the study \\
$\square$ & $\square$ ChIP-seq \\
$\square$ & $\square$ Flow cytometry \\
$\square$ & $\square$ MRI-based neuroimaging
\end{tabular}

